\title{
SEPARACION CUALI Y CUANTITATIVA DEL MANGANESO
}

Algunos reductores inorgánicos cuando están en medio ácido al mismo tiempo que reducen al $\mathrm{MnO}_{2}$ lo disuelven formando sales de los ácidos que intervienen en el medio, lo que constituye un método práctico para la obtención de las diversas sales del manganeso a partir de los óxidos saturados, un ácido y un reductor; estas sustancias pueden ser sulfitos, tiosulfatos, peróxido de hidrógeno, sulfato ferroso, ácidos hidrácidos halogenados, etc. Existen también reductores crgánicos que actuando en medio ácido disuelven a los óxidos del manganeso de origen natural o artificial, entre esas sustancias se encuentra el ácido oxáliço, este ácido que actúan como reductor puede disolver los referidos óxidos: $\mathrm{MnO}_{2}-\mathrm{Mn}_{2} \mathrm{O}_{3}-\mathrm{Mn}_{3} \mathrm{O}_{4}$ sin el agregado de alguna otra sustancia de carácter ácido, los derivados orgánicos de la hidroxilamina también favorecen la pronta disolución de los óxidos del manganeso, sin embargo las sales ácidas de la hidroxilamina, hidracina, semicarbazida al mismo tiempo que reducen a divalente al manganeso favorecen la pronta disolución del manganeso bien sea en medio ácido como en medio básico, por ejemplo en presencia de amoníaco o de hidróxido alcalino, basándose en esta característica se ha elaborado un sencillo procedimiento que permite separar con una gran facilidad al manganeso del fierro $u$ otros componentes.

Los minerales de manganeso: los óxidos, cuando son tratados con las sales de los ácidos minerales de la hidroxilamina, hidracina, semicarbazida, etc., en presencia de $\mathrm{NH}_{3}$ se disuelven instantáneamente dejando a los otros componentes que constituyen conjuntamente el mineral, sin ser atacados, lo que puede ser de un gran interés para la Mineralogía. Los diferentes análisis realizados con piroluxița, hausmanita, braunita comprueban lo ante dicho y ya G. Lunge (1) así como Fresenius y Mohr (2) han establecido respectivamente métodos, hoy clásicos, que permiten determinar al manganeso de sus óxidos, métodos que tienen idéntico principio, esto es, tratan a los óxidos del manganeso, piroluxita, etc. con una sustancia reductora, sulfato ferroso o ácido oxálico tomando ácido sulfúrico. Por otra parte Bunsen en un método

(1) Chem, Techn. Untersuchungsmethoden. 6 edicion Tomo I Pág. 59.

(2) Química Analítica Cuantitativa Treadwell 11 Edición Pág. 535. 
modificado por Rupp (3) determina a los óxidos que pueden liberar cloro del clorhídrico por un procedimiento especial y del cual tratan los textos de Química Cuantitativa.

Procedimiento: A 1 gr. del mineral de manganeso (Braunita, Hausmanita, Piroluxita) finamente pulverizado se le seca en un pesa filtro a $120^{\circ}$ a peso constante, hay que tener presente que los minerales son higrocópicos. La cantidad que se pesa al principio puede ser cualquier cantidad arbitraria; del pesa filtro se pasa algo a un vaso de precipitaciones procurando que sea alrededor de 0,5 de gramo, se establece el peso exacto por diferencia de pesada y se agrega por cada 0.25 de mineral 1 gr. de hidroxilamina 0 cualquiera de los otros reactivos nombrados (semicarbazida o hidroxilamina) se aconseja tomar el sulfato, se agregan $50 \mathrm{ml}$. de agua, exceso de $\mathrm{NH}_{s}$ y se calienta uno o dos minutos, tiempo en el que quedará disuelto todo el manganeso, lo que se reconoce por la desaparición de todos los puntos negros que proceden del mineral, se filtra y se lava repetidas veces y se determina al manganeso gavimétrica y volumétricamente. En el primer caso se puede determinar al manganeso según el método de Vohlard (4) y Gooch que en este caso consistiría en agregar como lo indican dichos autores ácido sulfúrico a la solución de manganeso que se encuentra en un crisol de porcelana, se evapora cuidadosamente, se tapa y se caliento hasta unos $480^{\circ}$ - a mayor temperatura se descompone el sulfato- se enfría el sulfato y se pesa. Se puede determinar al manganeso como óxido manganoso mangánico (6) precipitando al manganeso agregando al líquido obtenido de disolver los óxidos del manganeso, hidróxido de amonio y después cuidadosamente tribromuro de potasio o de sodio; se'hierve la solución y después se filtra en papel libre de cenizas. Se incinera en crisol de porcelana según lo indicado por Gooch (7) a una temperatura cerca de los $1000^{\circ}$.

Tanto al efectuar la disolución de los óxidos del manganeso como al realizar la precipitación con tribromuro de potasio es necesario tener cubierto el depósito en el que se realiza la disolución y oxidación pues se realizan desprendimientos de gases que pueden producir pérdida por proyección:

$$
2 \mathrm{MnO}_{2}+2 \mathrm{NH}_{2} \mathrm{OH}+4 \mathrm{HC} 1=2 \mathrm{MnC1}_{2}+\mathrm{N}_{2} \mathrm{O}+5 \mathrm{H}_{2} \mathrm{O}
$$

debemos hacer notar que no se desprende en ningún caso cloro si es que se actúa con los reductores indicados y que el ácido clorhídrico que figura en la reacción es el de la sal clorhídrica del compuesto y que sería preferible tomar al sulfato.

Al agregar tribromuro de potasio el bromo actúa sobre el hidróxido de amonio en la forma conocida dando hipobromito, bromuro y nitrógeno:

(3) Che Stg. 52,429 (1928).

(4) Ann d. Chem. U. Pharm 198 Pág. 238.

(5) Zeitsch F. Anorg. Ch. 17 Pág. 264 (1898).

(6) Zeitsch. F. Anorg. Ch. Pág. 104 (1908).

(7) Loc. Cit. 


$$
\begin{aligned}
& \mathrm{Br}_{2}+2 \mathrm{NH}_{4} \mathrm{OH}=\mathrm{NH}_{1} \mathrm{Br}+\mathrm{NH}_{4} \mathrm{OBr}+\mathrm{H}_{2} \mathrm{O} \\
& 2 \mathrm{NH}_{3}+3 \mathrm{NH}_{4} \mathrm{OBr}=3 \mathrm{NH}_{4} \mathrm{Br}+3 \mathrm{H}_{2} \mathrm{O}+\mathrm{N}_{2}
\end{aligned}
$$

La determinación volumétrica (8) o calorimétrica (9) se puede efectuar según Clain (10) o Volhard evaporando la solución con sulfúrico hasta que comiencen a desprenderse vapores de anhidrido sulfúrico para estar seguro de que no hay ácido clorhídrico y que se ha destruído todo el reductor; entonces se diluye y se procede en cualquiera de la formas conocidas.

En la Marcha Analítica Cualitativa, cuando se trata de separar al manganeso del fierro y de los demás elementos con los que él precipita, la solución procedente del grupo del ácido sulfhídrico (11) y en caso de que no contenga oxalatc, fosfato o fluoruro, se le añade cloruro de amonio, se hierve y se le hace pasar durante algún tiempo ácido sulfhídrico, después de esto se le agrega hidróxido de amonio poco a poco hasta reacción alcalina y sin dejar de hacer pasar la corriente de gas sulfhídrico se continúa hasta que desaparece el olor amoniacal. Se agrega de nuevo hidróxido de amonio y también sulfhídrico, después de lo cual se deja en reposo al precipitado y se observa si ha ido todo al fondo, se investiga si todo ha precipitado agregando sulfhídrico, si todo hubiera precipitado entonces se procede a la separación de los elementos de este grupo, para esto se filtra y se lava repetidas veces el precipitado con una mezcla de sulfuro de amonio y agua que contiene unos cinco gramos de cloruro de amonio por $100 \mathrm{ml}$. de agua; ahora se añade una solución de carbonato de amonio para eliminar al uranilo y se disuelve el precipitado residual en ácido clorhídrico con lo que se disolverán los hidróxidos de las Tierras Raras, el de aluminio, cromo, y berilio y los sulfuros de fierro, manganeso, zinc, níquel cobalto; se concentra la solución clorhídrica y se agrega hidróxido de sodio en exceso y peróxido de hidrógeno o en lugar de este último tribromuro de potasio, con lo que precipitan el fierro y el manganeso junto con las Tierras Raras; ahora se disuelve el precipitado en clorhídrico y se agrega peróxido de hidrógeno y se hierve, se añade una sal mineral de hidroxilamina o de hidrazina o semicarbazida, se calienta ligeramente procurando que la solución tenga siempre su reacción alcalina por la presencia de hidróxido de amonio o de sodio al $10 \%$ con lo que quedará disuelto todo el manganeso y para reconocerlo se puede emplear la mezcla fundente oxidante después de volver a reprecipitar agregando a la solución alcalina peróxido de hidrógeno.

(8) Ann der Ch. U. Pharm 198 Pág. 318.

(9) Chem. Newa 83 Pág. 76 (1904).

(10) Ch. Zentralbl Pág. 1487 (1911).

(11) W. Boetger, Análisis Cualitétivo, 7 edición, Pág. 443. 